\title{
Intracranial blood flow velocity after head injury: relationship to severity of injury, time, neurological status and outcome
}

\author{
Kwan-Hon Chan, J Douglas Miller, N Mark Dearden
}

\begin{abstract}
Middle cerebral artery (MCA) blood flow velocity was measured daily by transcranial Doppler ultrasonography in 121 patients with severe (50), moderate (16) and minor (55) head injury during their hospital stay, and the results compared with findings in control subjects. Admission MCA velocity was significantly lower after severe $35.8(31 \cdot 9-39 \cdot 7) \mathrm{cm} / \mathrm{s}$, mean (95\% confidence limits), moderate 45.5 $(40.0-51.0) \mathrm{cm} / \mathrm{s}$ and minor 51.7 $(47 \cdot 9-55 \cdot 5) \mathrm{cm} / \mathrm{s}$ head injury when compared with normal controls 60.1 $(56 \cdot 9-63 \cdot 3) \mathrm{cm} / \mathrm{s}$. Initial mean velocity in severe head injury was significantly lower than in moderate and minor injury. At discharge, MCA velocity in severe injury remained below normal 46.2 $(43 \cdot 2-49 \cdot 0) \mathrm{cm} / \mathrm{s}$, whereas, in moderate and minor injury flow velocity had returned to normal. Correlation ( $r=0.46$, $p<0.01$ ) was found between MCA velocity and Glasgow Coma Score (GCS) on admission but not on discharge. Persistently low flow velocity was found in all 10 patients who died within 72 hours (early deaths). An admission MCA velocity of less than $28 \mathrm{~cm} / \mathrm{s}$ correctly predicted $80 \%$ of the early deaths. Patients who made a good recovery or had only moderate disability at six months showed a significant increase in velocity from admission $36 \cdot 2(31 \cdot 5-41 \cdot 2) \mathrm{cm} / \mathrm{s}$ to discharge 47.8 $(43.7-51.9) \mathrm{cm} / \mathrm{s}$ in contrast to those who were severely disabled, in whom velocity generally remained low.
\end{abstract}

(F Neurol Neurosurg Psychiatry 1992;55:787-791)

Knowledge of the cerebral vascular circulation is fundamental to understanding the pathophysiology of head injury and its sequelae in individual patients. No ideal method yet exists to assess it. Measurements of regional cerebral blood flow by multichannel Xenon clearance and similar techniques are time consuming and may require transport of patients to a special facility, eliminating patients whose physiological status is unstable, rendering them unsafe to be moved from the Intensive Care Unit. $^{1-3}$

Within the past decade, transcranial Doppler ultrasonography (TCD) has been used to provide a portable, noninvasive system for repeated measurement of the velocity of blood flow in the main basal cerebral arteries through the intact cranium. ${ }^{4}$ We report on sequential daily measurements of blood flow velocity in patients with different severities of head injury. We examine the relationships between blood flow velocity and time after trauma, severity of injury, changes in the level of consciousness and clinical outcome.

\section{Material and methods}

The Head and Spinal Injury Unit in Edinburgh received all adult brain injured patients from the city of Edinburgh (population 500000 ) regardless of severity, as well as moderate and severe brain injuries from South East Scotland (population 1.2 million). Patients were managed by a standard protocol that included guidelines for CT scanning. These comprised all patients in coma and cases with skull fracture accompanied by depression of consciousness, abnormal neurological signs, or seizure activity, and patients with no skull fracture but impairment of consciousness or abnormal neurological signs that did not resolve within 24 hours.

Between August 1989 and July 1990, 121 patients (97 males and 24 females; mean age 39 years, range: 6 to 83 years) were included in this study. Only three were below 10 years of age. This series should therefore be regarded as descriptive of head injury in adults. All patients had sustained closed brain injury and had CT on admission. Patients were classified according to the post-resuscitation Glasgow Coma Score (GCS) into severe 50 (GCS $\leqslant 8$ with no eye opening), moderate 16 (GCS 9 to 12) and minor 55 (GCS 13 to 15) injury. Intracranial pathology was classified according to CT into focal (intracranial haematoma and/or unilateral contusion or swelling), diffuse and normal (no CT abnormality). Patients with a past history of medical illnesses (21), clinical findings suggestive of spontaneous cerebral vascular events (15) and those in whom satisfactory TCD examinations could not be performed (mainly due to patients' uncooperation) (33) were excluded.

All 50 severely injured patients were paralysed and sedated with continuous infusions of pancuronium and phenoperidine respectively and were ventilated to $\mathrm{PaCO}_{2}$ of $3 \cdot 5-4 \mathrm{kPa}$. They had continuous monitoring of blood pressure, arterial oxygen saturation $\left(\mathrm{SaO}_{2}\right)$, endtidal carbon dioxide concentration $\left(\mathrm{ETCO}_{2}\right)$ and body temperature. Forty-one of these had intracranial pressure monitoring. Haemoglobin concentration was measured daily. Patients with moderate and minor inju- 
ries were managed in a standard way with sequential neurological observations and assessments on the Glasgow Coma Scale.

To establish the normal values of flow velocity in the intracranial vessels of non-head injured adults, 20 individuals from the surgical ward (16 males and four females with a mean age of 41, range 16-64 years) and without past history of cerebral disease were studied. These comprised patients suffering from benign anorectal conditions (13), post-appendicectomy (3) and peptic ulceration (4).

Transcranial Doppler (Medasonics, California, USA) examination was first performed within 24 hours of admission, according to the method described by Aaslid. ${ }^{4}$ Both middle cerebral arteries (MCA) were insonated using the same window setting for each patient. The depth which gave the highest time-averaged mean flow velocity was chosen for recording. Measurements were taken from an average of at least 15 cardiac cycles. All patients had at least daily measurement of flow velocity during their entire hospital stay using the same depth setting for each examination. For patients with multiple daily measurements, the highest velocity value of the day was reported. Our normal value for time-averaged mean MCA flow velocity on the right and left sides in control subjects were $62(59 \cdot 3-64 \cdot 7)$ and 59 $(55 \cdot 9-62 \cdot 1)(95 \%$ confidence limits) $\mathrm{cm} / \mathrm{s}$. An abnormal increase in MCA flow velocity was defined as time-averaged mean velocity greater than $100 \mathrm{~cm} / \mathrm{s}$. During the TCD examinations, $\mathrm{SaO}_{2}$ was maintained above $95 \%$, mean was $3.5 \mathrm{kPa} \mathrm{ETCO}{ }_{2}$ (range 2.7-4.7) and mean haemoglobin concentration was $12.1 \mathrm{~g} / \mathrm{dl}$ (range 9.9-14). The coefficient of variation (standard deviation divided by mean) from day to day of $\mathrm{ETCO}_{2}$ and haemoglobin concentrations during TCD measurements were $13 \%$ and $11 \%$ respectively.

The outcomes of severely injured survivors were assessed at six months after injury using the Glasgow Outcome Scale. ${ }^{5}$ Brainstem death was defined according to the revised code of practice of the United Kingdom Department of Health and Social Security. ${ }^{6}$ Statistical analyses were by $t$ test with adjustment for previous value with time, analysis of variance and probability density estimation by the method of Kernel. ${ }^{7-10}$ Significance was taken at the $5 \%$ level.

\section{Results}

Table 1 shows the demographic data of the 121 studied cases. Two patients with severe injury and one with minor injury were below 10 years of age. The median durations of hospital stay in severe, moderate and minor injury were respectively 15 days (range: 2-39), five days (range: $3-17$ ) and two days (range 1-10).

The average of right and left MCA velocity was used for analysis since no consistent difference in MCA velocity between right and left sides were found either in different pathology categories or at different time periods.

Velocity in relation to severity of injury and time On admission, all patients with head injury had significantly lower velocity than that of normal controls; MCA velocity was lowest in patients with severe injury, significantly less than either moderate or minor injury (table 2). Velocity in patients with moderate injury was not significantly different from that in minor injury, but was significantly lower than in the control patients.

After admission, time-averaged mean MCA velocity values in patients with severe injury increased to lie within the normal range and became maximal by day 5 . Increased velocity to above $100 \mathrm{~cm} / \mathrm{s}$ was noted in 17 of the severely injured patients (unilateral rise in 9 and bilateral in 8) during the first week. Velocity then decreased gradually to below normal two weeks after severe injury (fig 1). The velocity on discharge was significantly lower than that seen in patients with moderate or minor injury and in normal control but higher than at admission (table 2).

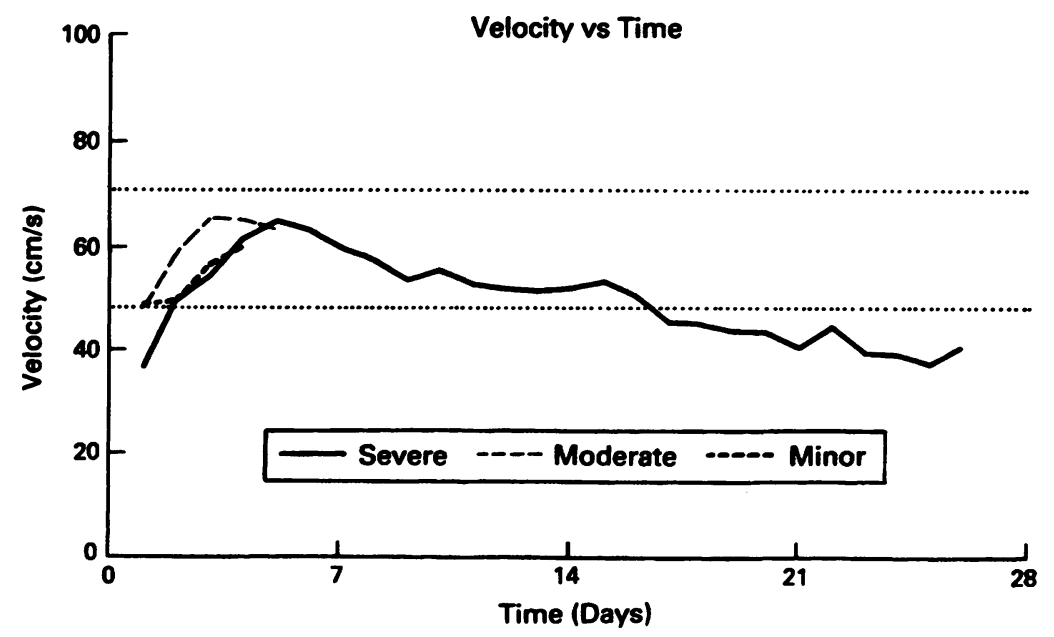

Figure 1 Plot of velocity against time in severe, moderate and minor head injury (dotted lines represent normal velocity $\pm 2 S D)$.
Table 1 Demographic data for the study population

\begin{tabular}{llll}
\hline & $\begin{array}{l}\text { Severe } \\
\text { Injury }\end{array}$ & $\begin{array}{l}\text { Moderate } \\
\text { Injury }\end{array}$ & $\begin{array}{l}\text { Minor } \\
\text { Injury }\end{array}$ \\
\hline Number & 50 & 16 & 55 \\
Male/female & $43: 7$ & $12: 4$ & $42: 13$ \\
$\begin{array}{l}\text { Mean age (range) } \\
\text { CT findings: }\end{array}$ & $29(6-59)$ & $37(14-83)$ & $49(6-79)$ \\
$\begin{array}{l}\text { focal/diffuse/normal } \\
\text { Multiple injuries }\end{array}$ & $28 / 22 / 0$ & $13 / 3 / 0$ & $26 / 5 / 24$ \\
\hline
\end{tabular}

Table 2 Velocity on admission and discharge in patients with different severities of injury

\begin{tabular}{lll}
\hline Severity of & $\begin{array}{l}\text { Admission } \\
\text { velocity } \\
\text { mean }(95 \% \text { confidence }\end{array}$ & $\begin{array}{l}\text { Discharge } \\
\text { velocity }\end{array}$ \\
\hline Severe & $35 \cdot 8(31 \cdot 9-39 \cdot 7)$ & $46 \cdot 2(43 \cdot 4-49 \cdot 0)$ \\
Moderate & $45.5(40 \cdot 0-51 \cdot 0)$ & $58 \cdot 1(54 \cdot 1-62 \cdot 1)$ \\
Minor & $51 \cdot 7(47.9-55 \cdot 5)$ & $57.5(55 \cdot 4-59 \cdot 6)$ \\
Normal & $60.1(56.9-63 \cdot 3)$ & \\
\hline
\end{tabular}

See text for statistical relationships.

Velocity in $\mathrm{cm} / \mathrm{s}$. 


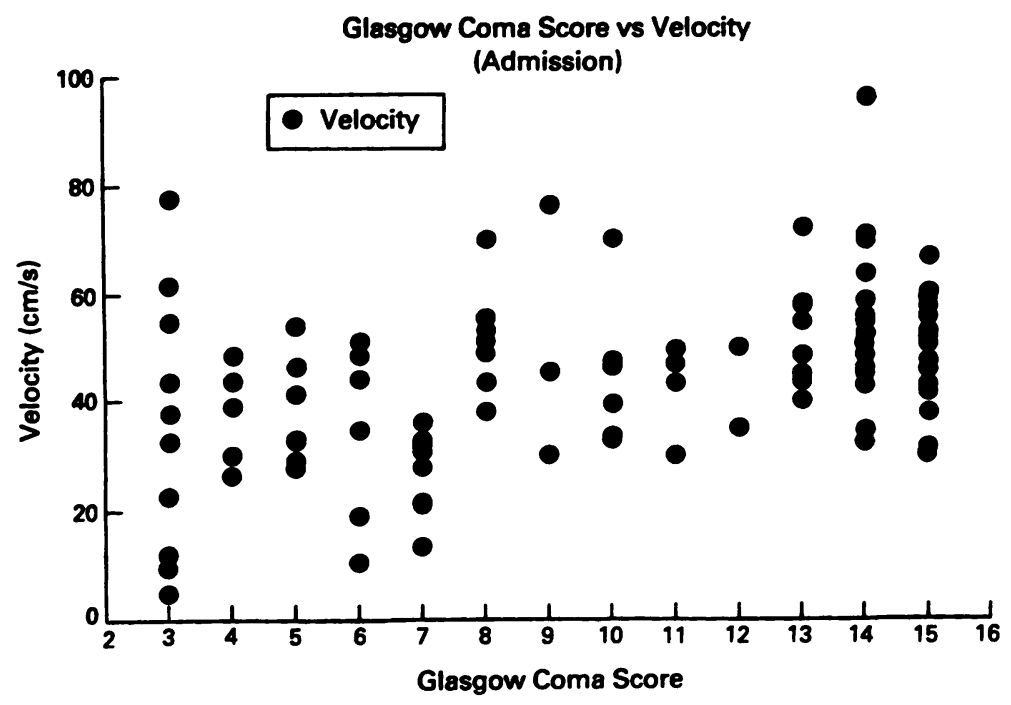

Figure 2 Plot of velocity against Glasgow Coma Score on admission in 121 patients studied.

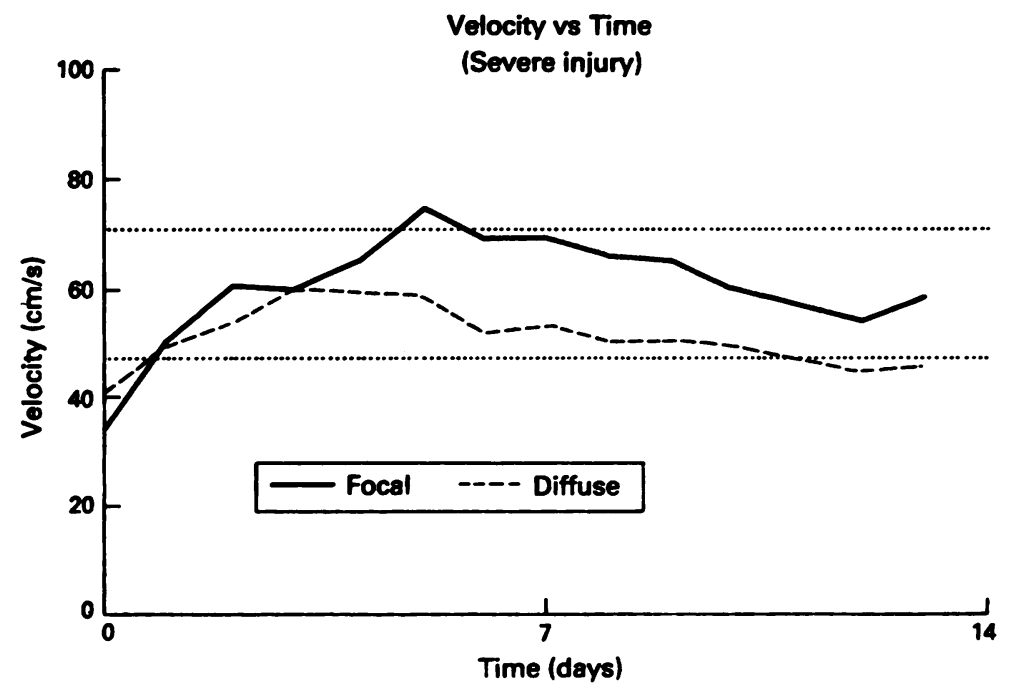

Figure 3 Plot of velocity against time in 22 (11 cases with focal lesion and 11 with diffuse injury) patients with severe head injury (dotted lines represent normal velocity $\pm 2 S D)$.

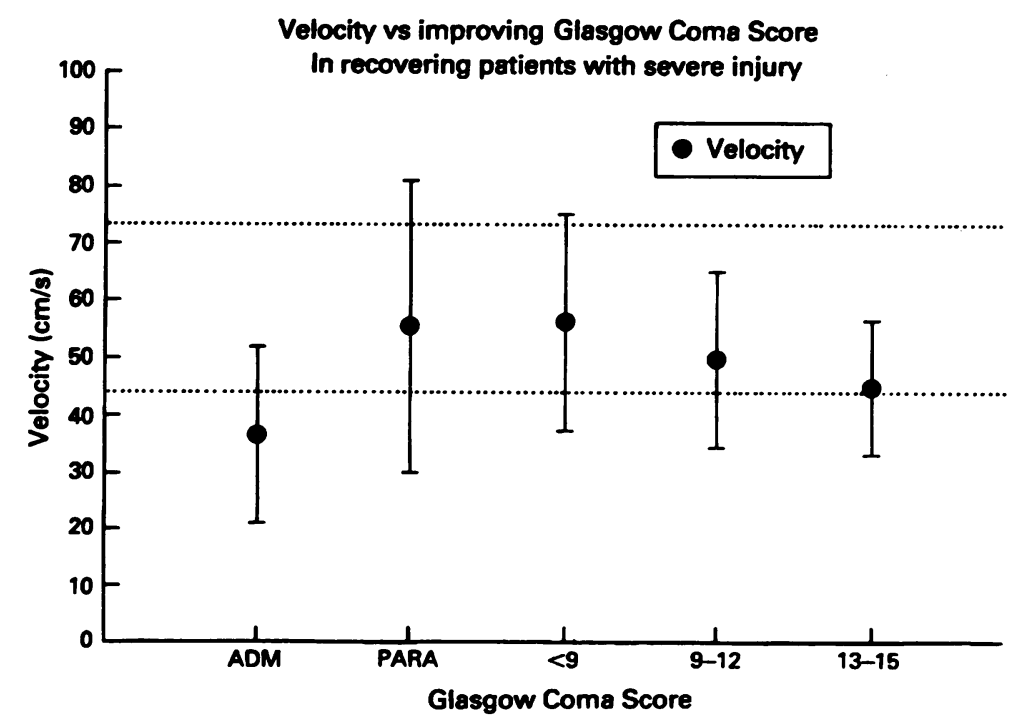

Figure 4 Plot of velocity ( \pm SD) against Glasgow Coma Score in patients recovering from severe head injury (dotted lines represent normal velocity $\pm 2 S D, A D M=$ admission, PARA = patients being paralysed).
The time-averaged mean MCA flow velocity in patients with moderate and minor head injury returned to normal within two days of admission and showed no difference until discharge. Velocity at discharge in patients with moderate injury was significantly higher than admission. Although velocity on discharge was higher than that on admission in minor injury, statistical significance could not be demonstrated. Increased velocity to above $100 \mathrm{~cm} / \mathrm{s}$ was noted in three patients with moderate (unilateral rise in two and bilateral in one) and three with minor injury (all with unilateral rise) within the first five days.

Velocity in relation to Glasgow Coma Score and time

Rank correlation ( $\mathrm{r}=0.46, \mathrm{p}<0.01)$ was noted between the MCA velocity and GCS on admission (fig 2). In 22 severely injured survivors (11 focal and 11 diffuse injury), MCA velocity data in relation to time and changes in GCS were available for statistical study. A significant increase in velocity in the days after admission was noted in patients with both focal and diffuse injury ( $p<0.01$, analysis of variance) reaching a peak at days 6 and 5 respectively (fig 3). Statistical differences between the focal and diffuse injury groups could be shown at days 6 and 7 . In patients with focal injury, unilateral increase in MCA velocity to above $100 \mathrm{~cm} / \mathrm{s}$ was found in six patients and bilateral rise in velocity in two cases. In diffuse injury, unilateral and bilateral velocity increase occurred in two patients each.

The flow velocity in these 22 patients increased to a peak while they were paralysed and ventilated (fig 4). Velocity decreased thereafter as GCS improved, but remained at a higher level than at admission.

\section{Velocity in relation to outcome (severe injury)}

The daily velocity was analysed in relation to clinical outcome at six months after injury. The five point Glasgow Outcome Scale was collapsed to three outcome groups: 1) death or persistent vegetative state $(15) ; 2)$ severe disability (9) and 3) moderate disability and good recovery (26). There was no correlation between changes in the daily MCA velocity and allocation to any of the three outcome groups.

Of the 50 severely injured patients studied, 15 died and 35 were discharged. Velocity on discharge in 27 patients in whom GCS improved to $13-15$ points $45 \cdot 3(40 \cdot 1-50 \cdot 5) \mathrm{cm} / \mathrm{s}$, mean (95\% confidence limits) was not significantly different from 8 cases whose GCS score remained below 13 points 39.3 $(36 \cdot 1-42 \cdot 5) \mathrm{cm} / \mathrm{s}$.

Further analysis revealed that 10 patients who died within 72 hours of injury (early deaths) had persistently low flow velocity and five who died after 72 hours (late deaths) had normal admission velocity. The admission velocity of the early deaths was significantly lower than in the remaining severely injured 
survivors (table 3 ). Probability density analysis revealed an admission MCA flow velocity of $28 \mathrm{~cm} / \mathrm{s}$ as the cut off point which predicted early death. Velocity of less than $28 \mathrm{~cm} / \mathrm{s}$ would correctly predict $80 \%$ of early deaths. Flow velocity recorded in late deaths increased further after admission and exceeded $100 \mathrm{~cm} / \mathrm{s}$ during certain periods of recording in four patients. Their velocity subsequently decreased to a low level before death. Similar high flow velocity levels were also observed during some periods after admission in 13 patients who survived. High flow velocity was not a predictive factor for mortality.

Separate analysis of the 35 survivors revealed that the MCA velocity on admission and discharge of patients who remained severely disabled was not significantly different from those with moderate disability or good recovery (table 3). However, MCA velocity increased over time in patients in the latter group and the discharge velocity was significantly higher than that on admission.

Velocity in relation to brain stem death

Of the 15 patients who died, 11 had recordable MCA velocity after brain stem death had been declared. Three evolving patterns of velocity change were observed: 1) small systolic spikes which were present from admission until death; 2) preservation of systolic and diastolic velocity on admission but development of reverberant (antegrade and retrograde) flow pattern which persisted after brain stem death had been declared; 3 ) very low systolic and diastolic velocities $(<20 \mathrm{~cm} / \mathrm{s})$, recordable from admission to death. In four patients, the MCA velocity trace which was present initially was no longer recordable after brain stem death.

\section{Discussion}

Intracranial blood flow velocity is proportional to cerebral blood flow (CBF) and inversely related to the calibre of the insonated vessel. Since the diameter of the vessel being studied is unknown and the relationship between flow velocity and CBF is nonlinear, velocity measurement cannot be considered as a direct reflection of CBF. ${ }^{11}$

Changes in the cerebral circulation after brain injury of differing degrees of severity have been described. ${ }^{312-14}$ These results were based on separate observations made days apart and the severity of injury was often not uniformly classified. Radioisotope study has

Table 3 Relationship between admission and discharge velocity and outcome

\begin{tabular}{|c|c|c|}
\hline Outcome & $\begin{array}{l}\text { Admission } \\
\text { velocity } \\
\text { mean ( } 95 \% \text { confidence }\end{array}$ & $\begin{array}{l}\text { Discharge } \\
\text { velocity } \\
\text { e limits) }\end{array}$ \\
\hline $\begin{array}{c}\text { Dead, }<72 \text { hours } \\
>72 \text { hours } \\
\text { mean } \\
\text { Severe disability }\end{array}$ & $\begin{array}{l}18 \cdot 1(10 \cdot 2-26 \cdot 0) \\
45 \cdot 7(38 \cdot 3-53 \cdot 1) \\
30.6(18 \cdot 5-42 \cdot 7) \\
43.6(35.3-51.9)\end{array}$ & $42.4(35 \cdot 6-49 \cdot 2)$ \\
\hline $\begin{array}{l}\text { Moderate disability } \\
\text { or good recovery }\end{array}$ & $36 \cdot 2(31 \cdot 2-41 \cdot 2)$ & $47.8(43.7-51.9)$ \\
\hline
\end{tabular}

shown that traumatic brain injury is associated with prolongation of the cerebral transit time. ${ }^{15}$ Cerebral blood flow, measured by various techniques, was reduced less in moderately than in severely injured patients within the first week of admission. ${ }^{13}{ }^{16-19}$ Experimentally, increasing degree of brain trauma was associated with increasing impairment of $\mathrm{CBF}^{20}$ Our results support these previous findings, but in interpreting measurements of flow velocity it is important to consider whether the data may be explained by changes in haematocrit, arterial carbon dioxide concentration or sedative drugs, all of which may influence measurements. There was no systematic change in haemoglobin concentration in patients sufficient to explain the results. While some decrease in flow velocity observed in the study population might have been related to the reduction in arterial carbon dioxide concentration and use of sedation in severely injured patients, this could only partly explain the velocity decreases that were observed. Moreover, velocity remained low after the first two weeks of injury, long after the arterial carbon dioxide concentration had returned to normal and sedative drugs were no longer used. This suggests that the severity of injury was the main factor relating to the decrease in MCA flow velocity. Sedation and hyperventilation were not used in patients with moderate and minor injury. Velocity decreases seen in these cases may be partly due to classification of patients based on GCS alone, which did not take pathology into consideration. The fact that we included only patients who had CT performed might have led to selection of cases with more significant intracranial lesions. Reductions in CBF after focal brain damage have been described. ${ }^{161821}$ Brain lesions can be detected by MRI or PET in patients with minor head injury despite a normal CT and little or no impairment in consciousness. ${ }^{22} 23$ Neuropsychological impairment has also been observed at follow up of such patients. ${ }^{22-25}$ Multifocal traumatic brain lesions may therefore be a more prominent pathological feature of moderate and minor head injury than previously recognised. ${ }^{24-27}$ Although MCA flow velocity improved to normal on discharge in such cases, this did not necessarily predict full functional recovery.

It is known that flow velocity in very young children is higher than in adults and may therefore confound the interpretation of data. ${ }^{28}$ In this series there were few children, none under five years of age, and in only one of these was increased velocity recorded $(121 \mathrm{~cm} / \mathrm{s})$.

A correlation between flow velocity and GCS score has not been reported previously. However, CBF studies have shown a positive relationship between volume flow and clinical neurological function within 24 hours of injury. ${ }^{129}$ After admission, increasing CBF levels have been found to correlate with progressive improvement of clinical neurological status, but only after abnormally high flow values have been excluded. ${ }^{13}$ Our analysis included high flow velocity recordings and 
similar relationships could not be demonstrated. High flow velocity may be due either to post-traumatic increase of CBF (cerebral hyperaemia) or narrowing (vasospasm) of the major cerebral arteries with different prognostic significance. ${ }^{1330}$ These velocity increases have been separately studied by us in detail. Such changes probably played a major role in the peaking of flow velocity at the end of the first week after injury. Clinical improvement might have accompanied some of the velocity increases but could not be assessed directly because of muscle paralysis and sedation.

Angiographic and radioisotopic assessments of cerebral circulation time have shown that slowing of the circulatory transit times are associated with a poor outcome. ${ }^{3132} \mathrm{CBF}$ values are predictive of death only when they achieve a low of less than $25 \mathrm{ml} / 100 \mathrm{gm} /$ minute or reach a high of more than $70 \mathrm{ml}$ $100 \mathrm{gm} /$ minute. $^{1314}$ Our findings were in only partial agreement. Low velocity did, but high flow velocity did not, predict poor outcome. Normalisation of CBF within several days of injury has been reported to be a favourable sign after severe injury. ${ }^{13} 14$

Different patterns of TCD signal have been described after intracranial circulatory arrest ranging in downward progression from reverberant flow, systolic spikes, to no flow, and these have been correlated with the sites of angiographic cessation of CBF at different stages of intracranial circulatory arrest. ${ }^{33}$ Our results are compatible with TCD examinations at these different stages.

The value of MCA flow velocity recorded on admission provides useful confirmation of the severity of injury, for example, in patients who arrive already intubated and ventilated. In addition, TCD may add useful information for predicting a poor outcome at an early stage following head injury. It also provides a noninvasive means of estimating cerebral perfusion pressure. Since arterial pressure is easily determined, TCD velocity change can be used to indicate the presence of increased intracranial pressure. ${ }^{34}$ Increased flow velocity, which may be the result of vasospasm or hyperaemia can also be detected non-invasively. These two conditions are respectively important causes of cerebral ischaemia and raised intracranial pressure after head injury, and have major implications for the choice of therapy in the management of brain injured patients.

The authors are indebted to Bill Adams of the department of Medical Statistics for his assistance in statistical analysis.

This study was supported by the Medical Research Council special project grant (SPG 880 9197). K-H Chan was supported by the Croucher Foundation Research Fellowship and the University of Hong Kong.

1 Andrews PJD, Piper IR, Dearden NM, Miller JD. Secondary insults during intrahospital transport of head-injured patients. Lancet 1990;335:327-330.

2 Bruce DA, Langfitt TW, Miller JD, et al. Regional cerebral blood flow, intracranial pressure and brain metabolism in comatose patients. $\mathcal{F}$ Neurosurg 1973;38:131-44.

3 Dickman CA, Carter LP, Baidwin HZ, Harrington T, Tallman D. Continuous regional cerebral blood flow monitoring in acute craniocerebral trauma. Neurosurg 1991;28:467-72.
4 Aaslid R, Markwalder TM, Nornes H. Noninvasive transcranial Doppler ultrasound recording of flow velocity in basal cerebral arteries. $\mathcal{f}$ Neurosurg 1982;57:769-74.

5 Jennet $B$, Bond $M$. Assessment of outcome after severe brain damage. A practical scale. Lancet 1975;1:480-4.

6 Revised code of practice for organ transplantation. $B M \mathcal{F}$ 1983;286:987.

7 Kenward MG. A method for comparing profiles of repeated measurements. F Roy Stat Soc (Series C, Applied Statistics) $1987 ; 36: 296-308$.

8 Rao CR. Some statistical methods for comparison of growth curves. Biometrics 1958;14:1-17.

9 Rowell JG, Walters RE. Analysing data with repeated observations on each experimental unit. $\mathcal{F}$ Agri Sci Camb 1976;87:423-32.

10 Silverman BW. Probability density method of Kernel in density estimation for statistics and data analysis. London: Chapman and Hall, 1975

11 Halsey JH, McDowell HA, Gelmon S, Morawetz RB. Blood velocity in the middle cerebral artery and regional cerebral blood flow during carotid endarterectomy. Stroke 1989;20:53-8.

12 Muizelaar JP, Obrist WD. CBF and brain metabolism with brain injury. In: Becker DP and Povlishock J, eds Central nervous system trauma: status report. National Institute of Communicative Disorder and Stroke 1985:123-38.

13 Obrist WD, Gennarelli TA, Segawa H, Dolinskas CA, Langfitt TW. Relation of cerebral blood flow to neurological status and outcome in head-injured patients. $\mathcal{F}$ Neurosurg 1979;51:292-300.

14 Overgaard J, Tweed WA. Cerebral circulation after head injury. I Cerebral blood flow and its regulation after closed head injury with emphasis on clinical correlations. f Neurosurg 1974;41:531-41.

15 Taylor AR, Bell TK. Slowing of cerebral circulation after concussional head injury. A controlled trial. Lance 1966;2:178-180.

16 Enevoldsen EM, Cold G, Jensen FT, Malmros R. Dynamic changes in regional $\mathrm{CBF}$, intraventricular pressure, CSF $\mathrm{pH}$ and lactate levels during the acute phase of head injury. I Neurosurg 1976;44:191-214.

17 Fieschi C, Battistini N, Beduschi A, Boselli L, Rossanda M. Regional cerebral blood flow and intraventricular pressure in acute head injuries. $\mathcal{F}$ Neurol Neurosurg Psychiat 1974;37:1378-88.

18 Marion DW, Darby J, Yonas H. Acute regional cerebral blood flow changes caused by severe head injuries. Neurosurg 1991;74:407-14.

19 Rappaport ZH, Ransohoff J, Hass W. Cerebral metabolism in head trauma. Progress in neurological surgery, Vol 10. In Krayenbuhl H, Maspes PE, eds. London: S Karger, 1981:1-13.

20 Lewelt W, Jenkins LW, Miller JD. Autoregulation of cerebra blood flow after experimental fluid percussion injury of the brain. $\mathcal{f}$ Neurosurg 1980;53:500-11.

21 Cold GE, Jensen FT. Cerebral blood flow in the acute phase after head injury. Pt 1: Correlation to age of the patients, clinical outcome and localisation of the injured region. Acta Anaesth Scand 1980;24:245-51.

22 Langfitt TW, Obrist WD, Alavi A. Regional structure and function in head-injured patients : correlation of CT, MRI, PET, CBF and neuropsychological assessment. In: Levin HS, Eisenberg HM, Grafman J, eds. Neurobehavioural recovery from head injury. New York: Oxford vioural recovery from head injur
University Press, 1987:31-42.

23 Levin HS, Amparo E, Eisenberg HM, et al. Magnetic resonance imaging and computerised tomography in relation to neurobehavioural sequelae of mild and moderate head injuries. $\mathcal{f}$ Neurosurg 1987;66:706-13.

24 Rimel RW, Giordani B, Barth JT, Boll TJ, Jane JA. Disability caused by minor head injury. Neurosurg 1981;9:221-8.

25 Rimel RW, Giordani B, Barth JT, Jane JA. Moderate head injury: completing the clinical spectrum of brain trauma. Neurosurg 1982;11:344-51.

26 Gronwall D, Wrightson P. Delayed recovery of intellectual function after minor head injury. Lancet 1974;2:605-9.

27 Gronwall D, Wrightson P. Cumulative effect of concussion. Lancet 1975;2:995-7.

28 Bode H, Eden A: Transcranial Doppler sonography in children. $f$ Child Neurol 1989;4(Supp):68-76.

29 Moruzzi $G$, Magoun $H W$. Brainstem reticular function and activation of EEG. Electroenceph Clin Neurophysiol 1945 1:455-73.

30 Miller JD, Gudeman SK. Cerebral vasospasm after head injury. In: Wilkins RH, ed. Cerebral arterial spasm. Proc 2nd Int Workshop, Amsterdam, The Netherlands. Baltimore: Williams and Wilkins, 1980:476-9.

31 Papo I, Caruselli G, Occhipinti C, DiPietrantoni F. Prognostic value of cerebral transit time (radiocirculography) in head injury. $f$ Neurosurg Sci 1973;17:208-11.

32 Scialfa G, Cristi GF. Prognostic value of cerebralangiography in nonsurgical cases of traumatic coma. angiography in nonsurgical cas

33 Hassler W, Steinmetz H, Pirschel J. Transcranial Doppler study of intracranial circulatory arrest. $\mathcal{f}$ Neurosurg $1989 ; 71: 195-201$.

34 Chan KH, Miller JD, Dearden NM, Andrews PJD, Midgley $S$. The effect of cerebral perfusion pressure upon changes in middle cerebral artery flow velocity and jugular venous bulb oxygen saturation after severe brain injury. $\mathcal{J}$ Neurosurg 1992;77:55-61. 